\title{
APPLYING THE CONSUMER DECISION MODEL TO ENFORCE MINIMUM AGE TOBACCO PURCHASING LAWS
}

\author{
Michael McCall, Donald W. Eckrich, and Patricia Libby \\ Ithaca College, NY, USA \\ KATHERINE GARMAN \\ Tennessee Department of Public Health, Nashville, TN, USA
}

\begin{abstract}
This paper describes how the consumer decision-making model can be applied to store clerks faced with determining which customers should be carded for the purchase of tobacco products. Assuming that this task induces a vigilant (high involvement) decision state, clerks $(N=256)$ rated four combined shopper-product profiles and assessed the likelihood that the shopper would be asked to provide identification. Results indicated that both age-related facial qualities and the gender of the customer contributed to the decision to request identification. The managerial implications and utility of the consumer decision model for enhancing compliance with minimum age purchasing laws are considered.
\end{abstract}

Store clerks are frequently placed in a position in which they must decide whether a customer should be asked for identification for the purchase of an agerestricted product. Recent federal laws that reemphasize the prohibition of sales of tobacco to persons under the age of 18 represent an important new challenge

Michael McCall, PhD, Department of Business Administration, School of Business, Ithaca College, NY, USA; Donald W. Eckrich, DBA, Department of Business Administration, School of Business, Ithaca College, NY, USA; Patricia Libby, PhD, Department of Accounting, School of Business, Ithaca College, NY, USA; and Katherine Garman, MPH, Tennessee Department of Public Health, Nashville, TN, USA.

This research was supported by a grant from the National Institute on Alcohol Abuse and Alcoholism (R29-AA10397-01) awarded to the first author.

Portions of this paper were presented at the $11^{\text {th }}$ annual meeting of the Association for Marketing Theory and Practice, Savannah, GA. (March, 2002).

Appreciation is due to reviewers including Dr. Marcia A. Finkelstein, Professor of Psychology, University of South Florida, Tampa, FL 33620-7200, USA; Dr. Gary E. Golden, Department of Business, Muskingum College, New Concord, OH 43762, USA and Dr Verlin B. Hinsz, Department of Psychology, North Dakota State University, Fargo D 58105-5075, USA.

Keywords: consumer behavior, judgment, decision making.

Please address correspondence and reprint requests to Dr. Michael McCall, Department of Business Administration, School of Business, Smiddy Hall, Ithaca College, Ithaca, NY. 14850. Phone (607)274-3501; Fax: (607)-274-1152; Email:<McCall@ithaca.edu> 
for store clerks. Similar to the more longstanding prohibition against the sale of alcohol to minors, the decision to request identification or proof of legal age and the ultimate determination of "legal age" again rest with the clerk. At present, there is little research that would inform a clerk on how best to make this important decision. In addition, there are implications for managers for mitigating potential liability by creating enhanced training sessions.

\section{BACKGROUND}

The issue of minors purchasing cigarettes represents a significant social and health problem. In 1992, it was estimated that nearly 1 billion packs of cigarettes were sold illegally to minors each year (U.S. Public Health Service, 1992). Notably, this is not only an American problem as tobacco usage among youth is extremely prevalent in Europe, Asia and South America. A majority of smokers begin using tobacco well before the age of 18 , and sometimes as early as age 12 . While the reasons for beginning tobacco use represent a complex interplay between social, sibling, and parental influences, the role of advertising has been identified as a significant influence as well. What remains clear, however, is that minors do continue to smoke and in significant numbers.

It is reasoned that compliance with federal law prohibiting the sale of tobacco to minors will go a long way in reducing these numbers. Yet, media reports suggest that nearly $40 \%$ of the store clerks surveyed had sold tobacco products to minors. A careful examination of the real world conditions under which store clerks are required to make this important decision suggests several relevant lines of decision theory research that may be helpful.

\section{Consumer Decision Processes}

The consumer decision-making literature describes a well known cognitive decision model (cf. Mowen \& Minor, 2001) that may have widespread utility for explaining the process used by store clerks. We propose that the 5-step model thought to guide the consumer choice process in product and service decisions is analogous to the process used by store clerks when determining which customers should be carded for tobacco purchases.

The first step in the model is problem identification or recognition that the customer initiates intent to purchase tobacco, an age-restricted product. The store clerk then searches for information that would assist in making the decision to request identification from the customer (cf. Bruner \& Pomazal, 1988). The search for information may be internal or external and may include variables such as the physical appearance of the customer, the types of products that the customer intends to purchase, or even the time of the day that a purchase is attempted. The legal ramifications of a decision error suggest that the clerk is operating under the high involvement hierarchy (Beatty \& Smith, 1987). As 
might be expected, judgments that are associated with high risks and costs are likely to encourage more intensive search efforts (Mowen \& Minor, 2001).

Just as consumers are likely to compare the available options and information that have been gathered through the search process, a store clerk might examine and evaluate the information available to him/her such as the facial characteristics of the shopper and the types of products being purchased. Collectively, products often serve to cue consumer lifestyles as well as potential age groupings (McCall, 1994). The decision maker, having collected and evaluated the available evidence, decides whether to ask the customer for identification. In the final step of the model, sometimes referred to as postdecisional behavior, the clerk then assesses whether the decision was indeed the correct one.

To summarize, store clerks who are placed in situations in which there is considerable pressure to make a decision would be most likely to use decision heuristics such as person-product prototypes to aid in deciding the age of a customer. That is, characteristics of the customer, the products purchased, and the degree of correspondence among these factors will contribute to the decision. It was predicted that store clerks would be less likely to ask for identification when the person variables and product prototype cues suggest that the target is "above the legal age." Although we have no a priori reason to suspect gender or opposite sex differences among store clerk responses, prior work in the alcohol area (cf. McCall, 1999) suggests that ease of purchasing may be differentially affected by gender.

\section{METHOD}

\section{Design OVERVIEW}

This research is part of a five-year investigation that examines the role of consumer lifestyle and purchasing patterns as they apply to training practices of store clerks who sell tobacco products and alcoholic beverages. The design for this study was a 4 (product profile: high school, college, adult/family, older adult) X 4 (person profile: high school, college, adult/family, older adult) X 2 (gender) fully balanced Greco-Latin Square. There were 2 sets of stimulus persons for each person profile and the order of presentation was counterbalanced.

\section{Participants}

Participants were 256 grocery checkers from 23 randomiy selected stores of a major grocery chain who participated in a consumer impression survey and who were compensated with $\$ 5$ each for their assistance. Store clerks tended to be female (188 female; 61 male), ranged in age from 18 to 68 years (mean age = 26.26), and were a fairly stable group of employees who had worked for the company an average of just over $31 / 2$ years (mean tenure $=43.22$ months). All 
checkers (over the age of 18) who were working at the store during the scheduled visit were given the opportunity to participate.

\section{Procedures}

Each store was visited a number of times and on different days of the week. Research assistants were set up in office areas within each of the stores. The stimuli were presented via videotape that was controlled by the experimenter. As part of the informed consent process, participants were informed that any information they provided would not be shared directly with the store managers or corporate staff. After completing a brief demographic survey, each checker was shown four vignettes, each matching one set of combined products and people. The product groupings consisted of 8 different products that, during extensive pretesting, were determined empirically to fit one of the four product categories (Cronbach Alphas .78-.87). Examples of the various products from each of the categories include candy (High School), snacks (High School), frozen and easyto-prepare foods (College), baby products (Adult-family), fresh foods, meats and vegetables (Adult-family), and finally, foods requiring longer preparation (Older Adult). Participants viewed a total of four vignettes each representing one level of the product groupings and stimulus targets. After each product-person profile was presented, clerks assessed the shopper on a variety of characteristics including how likely it was that they would ask the shopper for identification for the purchase of a tobacco product (i.e., cigarettes; $1=$ not at all likely, 9= extremely likely). There were two key dependent variables for this study including: (1) How likely is it that you would card this person for the purchase of tobacco in a grocery store? (2) How typical are the products being purchased for an individual such as this consumer?

\section{RESULTS}

Initially, a set of preliminary analytic steps was taken to control for the potential of order by treatment interactions. That is, the Greco-Latin Square design shares some features with a standard repeated-measures design in that participants are exposed to multiple levels of the treatment; however, unlike a traditional repeated-measures design, participants do not receive all levels of treatment, even though the order of presentation is systematically varied. A multivariate analysis of variance was performed examining the effects of order for the stimulus persons and product groupings for the primary dependent variables. Results of this analysis revealed no significant interactions as a function of either variable $(F \mathrm{~s}<1.0)$. 


\section{Intentions to Request Identification for the Purchase of Tobacco}

As might be expected, the perceived age of the target was directly influenced by each of the key predictor variables. Strongest among these influences were the facial qualities of the target: an analysis of variance indicated that store clerks were very likely to request identification from a shoppers who appeared underage, and this tendency was strongly influenced by the faces of the shoppers, $F$ $(1,991)=522.75, p<.0001$. When respondents were presented with faces that suggested an older shopper, the presentation yielded lower carding intentions. Shoppers who appeared to be of high school age were most likely to be asked for identification for tobacco with college-aged shoppers the next most likely group. There was also a significant effect for target gender suggesting that males were, on average, much less likely to be asked for identification when seeking to purchase tobacco in a grocery store, $F(1,990)=6.38, p=.012$. The effect of facial quality was qualified by an important interaction: a face-by-target gender interaction, $F(3,990)=19.32, p<.001$. Further examination of the means for this interaction suggested that male high school customers were more likely to be asked for identification than were high school females, $M=8.44$ vs. $7.34, p<$ .05. Yet in the adult family category, it was the female who was most likely to be asked to provide identification, $M=4.68$ vs. $2.90, p<.05$. Female clerks were more likely to ask for identification than were male clerks, $F(3,918)=$ $14.15, p<.001$ and, the more closely matched the product-shopper profiles were, the more likely it was that the target would be asked to provide identification, $F$ $(1,1021)=4.71, p=.03$.

\section{DISCUSSION}

These data offer some important information that may be useful to both decision makers and those who train decision makers. First, they demonstrate a clear tendency among store clerks to process facial characteristics as well as other atmospheric characteristics associated with the purchasing process (see also McCall, Trobetta, \& Nattrass, 2002). The gender of the shopper also played a significant role in the decision-making process. This gender difference is an important question for future research. It is possible to speculate on at least one plausible explanation for this effect. That is, by definition, the request for identification is in part an adversarial transaction. The shopper knows for certain whether she or he is of legal age to purchase the restricted product. By attempting such a purchase, she or he is asking that the clerk essentially believe that she or he is "legal." From the clerk's perspective, the request for identification is a rejection of that belief and represents a challenge for "proof." It may be that under levels of high involvement, the respondent becomes less willing to engage in an adversarial transaction (McCall, 1994). 
These data suggest that the consumer decision model may provide a valuable theoretical framework for examining an important social issue. Store clerks are frequently presented with this type of problem when dealing with both tobacco and alcohol-related products. Resolution of the problem requires both a search and an evaluation of information. As people become more experienced in making decisions of this sort, their postdecisional state is more confident.

There is some literature arguing that vigilant (i.e., careful and deliberate) decision making is an optimal method for making decisions. When individuals engage in this type of decision making they apply systematic and organized searches for information, consider a variety of alternatives, and then evaluate each of the alternatives prior to making a decision. The key, however, may be that a more vigilant decision strategy is more effective, but only when store clerks are able to implement that strategy. Johnson, Driskell, and Salas (1997) have suggested that there are a number of decisional situations that may not afford the opportunity for an individual to "choose" among several alternative strategies. For instance, store clerks who have multiple customers in line during a busy store time or bartenders faced with many patrons during happy hour may not feel that they have time to process all possible information and then evaluate different decisional approaches. Rather, they are likely to take into account a considerable amount of tangible and intangible evidence when making an important decision and may rely on decision heuristics (Nisbett \& Ross, 1980; Tversky \& Kahneman, 1973).

\section{MANAGERIAL IMPLICATIONS}

The key to limiting access to age-restricted products is closely linked to improving the quality of decision making for those people responsible for enforcing the laws. A number of researchers have also proposed teaching decision makers how to evaluate and separate information in terms of importance and relevance. Consumer researchers refer to this notion as a compensatory model of choice (Wright, 1976), where the basic idea is that all information is not of equal value. Individuals who are engaged in a search process will tend to scan a wide evaluative field with weight or value being given to some information while other information is given less value. In the process the decision maker becomes more of an active participant in the interpretation of information. For instance, consider several of the shopper-product profiles that were used in this study. Assuming all possible combinations, there were shopper profiles matching college and even high school students, and product profiles that included baby care products. The clerk may reason that since most high school students do not have small children the shopper may be of legal age (McCall, 1994). Thus, the correct strategy would be to process facial information (high valence), and product information (usually low valence) except in those instances where 
facial cues are ambiguous or inconsistent with the age-restricted products being purchased. The inconsistency between the products and the shopper profile is the trigger that would initiate this extended search for additional information. The presentation of a set of baby care products in conjunction with a shopper profile that is consistent with the product set (i.e., a 30-40 year-old) might lead to a low involvement type of search.

Finally, it seems quite reasonable that future research could categorize both the types of information available to clerks when checking for identification and also the reliability of that information. The findings could then be fed directly to clerks via training and development workshops or in-service presentations and would also be of great value to public-policy analysts. For managers, the costs of the increased internal controls (Libby, Libby, \& Short, in press) must be weighed against the potential losses due to noncompliance. In turn, risks and costs could be lowered. At present there is a great deal of interest in modeling optimal-decision strategies, and addressing social issues. The consumer decision model offers an opportunity to generate testable hypotheses that are theory driven and socially focused.

\section{REFERENCES}

Beatty, S., \& Smith, S. (1987). External search effort: An investigation across several product categories. Journal of Consumer Research, 14, 84-89.

Bruner, G. C., \& Pomazal, R. J. (1988). Problem recognition: The crucial first stage of the consumer decision process. Journal of Consumer Research, 19, 53-63.

Johnson, J. H., Driskell, J. E., \& Salas, E. (1997). Vigilant and hypervigilant decision making. Journal of Applied Psychology, 82,(4), 614-622.

Libby, R., Libby, P. \& Short, D. (in press). Financial Accounting, (4th ed.). Burr Ridge, IL. McGraw-Hill//rwin.

McCall, M. (1994). Decision theory and the sale of alcohol. Journal of Applied Social Psychology, 24, 18, 1593-1611.

McCall, M. (1999). Physical attractiveness, mood, and the decision to card for the purchase of alcohol: Evidence for a mood management hypothesis. Journal of Applied Social Psychology, 29, 1172-1190.

McCall, M., Trombetta, J., \& Nattrass, K. (2002). Limiting underage alcohol purchases: An application of the consumer decision model. Journal of Business and Psychology, 17, 1-10.

Mowen, J. C., \& Minor, M. S. (2001). Consumer behavior: A framework. (pp. 170-194), SaddleRiver NJ.: Prentice-Hall.

Nisbett, R., \& Ross, L. (1980). Human inference: Strategies and shortcomings of social judgment. (pp. 273-296). Englewood Cliffs, NJ.: Prentice-Hall.

Tversky, A., \& Kahneman, D. (1973). Availability: A heuristic for judging frequency and probability. Cognitive Psychology, 5, 207-232.

U.S. Public Health Service. Prevention Report. (1992). Preventing tobacco use by youth.

Wright, P. (1976). Consumer choice strategies: Simplifying versus optimizing. Journal of Marketing Research, 11, 60-67. 